NOVEL SMALL MOLECULE DRUGS INHIBIT TUMOR CELL METABOLISM AND SHOW POTENT ANTITUMORIGENIC POTENTIAL

Christina Trojel-Hansen², Kamille Dumong Erichsen', Mette Knak Christensen ${ }^{1}$, Peter Buhl Jensen $^{1}$, Maxwell Sehested ${ }^{2}$, and Søren Jensby Nielsen ${ }^{2}$.

${ }^{1}$ TopoTarget A/S, Symbion, Fruebjergvej 3, DK-2100 Copenhagen, Denmark

${ }^{2}$ XPU Bartholin, Rigshospitalet 3731, TopoTarget A/S, Copenhagen Biocenter, Ole Maaløesvej 5, DK-2200 Copenhagen, Denmark

\title{
DISCLOSURES: NONE
}

Requests for reprints: Christina Trojel-Hansen, XPU Bartholin, Rigshospitalet 3731, TopoTarget A/S, Copenhagen Biocenter, Ole Maaløesvej 5, DK-2200 Copenhagen, Denmark. Phone: 4535456076; E-mail: chh@topotarget.com.

\footnotetext{
ABSTRACT

Background: Rapidly-dividing tumor cells have an increased demand for nutrients to support their characteristic unabated growth; this demand is met by an increased availability of nutrients such as amino acids through vasculogenesis, and by the enhanced cellular entry of nutrients through upregulation of specific transporters. Deprivation of intracellular amino acids or block of amino acid uptake has been shown to be cytotoxic to many established human cancer cell lines in vitro and in human cancer xenograft models.
} 
Results: In this paper we provide evidence that the two small molecule oxyphenisatine analogues TOP001 and TOP216 exert their anti-cancer effect by affecting tumor cell metabolism and inducing intracellular amino acid deprivation, leading to a block of cell proliferation. GCN2 mediated phosphorylation of eIF $2 \alpha$ as well as mTOR pathway inhibition supports the above notion. In addition these novel anti-cancer compounds inhibit DNA and protein synthesis and induce apoptosis in a broad spectrum of cancer cell lines. In vivo, the compounds induce tumour stasis and regression in mouse xenograft models of human breast, prostate, ovarian and pancreatic cancer, both when administered intravenously and orally.

Conclusion: In conclusion, these small molecules, built on a 1,3-dihydroindole-2-one scaffold, elicit strong anti-proliferative and cytotoxic activity and importantly a strong antitumorigenity is observed in in vivo xenograft models of human breast, ovary, prostate and pancreatic cancers encouraging the translation of this class of compounds into the clinic. 


\section{INTRODUCTION}

All mammalian cells regulate gene expression in response to changes in the external environment. Amino acid availability regulates cellular physiology by modulating gene expression and signal transduction pathways. The intracellular concentration of any given amino acid is governed by rates of amino acid influx and efflux via amino acid transporters, protein synthesis, protein turnover and aminoacyl-tRNA production, plus amino acid catabolism and biosynthesis. Mammalian cells have two recognized pathways for monitoring and responding to amino acid availability. These two pathways change the rate of protein synthesis in opposite directions(1-4). The mammalian target of rapamycin (mTOR) pathway functions to confirm that a sufficient level of amino acids is present intracellularly in order to support protein synthesis and cell growth. The mTOR pathway is activated by numerous extracellular signals including growth factors and nutrients via the insulin/insulin-like growth factor (IGF1) 1/phosphatidyl inositol-3-OH kinase (PI(3)K) and extracellular signal regulated kinase-p90 ribosomal protein S6 kinase (ERK-RSK) pathways(5-10). However, amino acid depletion overrides all other mTOR stimuli and results in pathway inhibition. Recent observations also indicate that Rag GTPases can physically interact with mTORC1 and regulate its sub-cellular redistribution in response to alterations in the levels of L-leucine(11-14). Activation of mTOR ultimately results in the phosphorylation of p70 S6 kinase $\left(\mathrm{p} 70^{\mathrm{S} 6 \mathrm{~K}}\right)$ and $4 \mathrm{E}-$ BP1. Activation of $\mathrm{p} 70^{\mathrm{S} 6 \mathrm{~K}}$ permits a high level of translation of mRNA species that encode ribosomal proteins thereby maintaining protein synthesis and cell growth rates consistent with nutrient availability, whereas 4E-BP1 phosphorylation stimulates the translation of mRNAs with structured 5'ends, such as those encoding for the growth regulators Myc and ODC(5). In addition amino acid deprivation regulates protein synthesis at the level of an increase in the amount of uncharged tRNAs. This in turn leads to a binding of uncharged tRNAs to the general control non- 
derepressible protein 2 (GCN2) kinase resulting in its activation. Once activated, GCN2 kinase phosphorylates the translation initiation factor eIF-2a, which leads to a strong decrease in global protein synthesis $(4,15-17)$.

We here demonstrate that two compounds TOP001 and the optimized analogue TOP216, belonging to a novel compound group based on a 1,3-dihydroindole-2-one scaffold, strongly inhibit the proliferation of cancer cells lines with striking selectivity (>1000 fold) against cancer cell lines that are insensitive to the compounds (18). In vivo, TOP001 and TOP216 show potent anti-cancer activity by inducing tumor regression (including cures) in mouse xenograft models of human tumours. We provide evidence that TOP216 may exert its function through depletion of intracellular amino acids. Treatment with TOP216 leads to increased levels of phosphorylated eIF2 $\alpha$ as well as decreased phosphorylation levels of mTOR substrates in sensitive cell lines, indicative of amino acid depletion. Taken together, these data suggest that TOP216 is able to deplete cancer cell lines of intracellular amino acids, despite the presence at high concentrations outside the cell. The control of amino acid provision is emerging as a powerful physiologic and pharmacologic mechanism for limiting cell proliferation. A deeper understanding of the mechanism of action of this interesting class of anti-cancer compounds may facilitate the progression into clinical trials, and will lead to the validation of novel targets for anti-cancer therapy. 


\section{MATERIALS AND METHODS}

\section{Reagents and compounds}

TOP001, TOP216 and TOP385 were synthesized as previously described(18). TAXOL® was purchased from (Bristol-Myers Squibb.); 96-well black Packard Viewplates from (Perkin Elmer), Leucine uptake $\left[{ }^{14} \mathrm{C}\right]$ Cytostar-T assay kit and $[3 \mathrm{H}]$ Thymidine $5 \mathrm{mCi} / \mathrm{mmol}$, from (Amersham). ZVal-Ala-D,L-Asp-flouromethylketone (zVADfmk) from (Bachem, Bubbendorf, Switzerland). Antibodies: phospho ACC(ser79), PathScan ${ }^{\mathrm{TM}}$ Multiplex Western Cocktail I: Phospho-p90RSK, Phospho-Akt, Phospho-p44/ 42 MAPK and Phospho-S6 Ribosomal, S6 ribosomal protein, S6 total protein; phospho p70 S6K (Thr389), phospho-eIF2 $\alpha$, eIF2 $\alpha$, phospho-GCN2 (Thr898), GCN2 (Cell Signaling Technology), GAPDH (Santa cruz).

\section{Cell culture}

All cell lines were obtained from ATCC (ATCC/LGC Promochem, Borås, Sweden). Cell culture reagents were obtained from Invitrogen except otherwise stated. All cell lines except MCF-10A were maintained according to American Type Culture Collection guidelines in RPMI medium containing $10 \%$ foetal Bovine Serum (FBS) $100 \mathrm{U} / \mathrm{ml}$ penicillin, and $100 \mu \mathrm{g} / \mathrm{ml}$ streptomycin. MCF-10A was maintained in mammary epithelial growth medium (MEGM) with singlequot addition (BPE, hydrocortisone, hEGF, insulin, gentamicin/amphotericin-B) (Clonetics/Cambrex Bio Science, Walkersville, USA). For experiments, cells were trypsinized and seeded in $75 \mathrm{~cm}^{2}$ flasks (Nunc) and allowed to grow overnight to reach $70 \%$ confluence at $37^{\circ} \mathrm{C}$ with $95 \% / 5 \%$ air/ $\mathrm{CO}^{2}$ and $80 \%$ relative humidity. Cells were treated drugs for indicated concentrations and periods. Cells were rinsed with PBS, harvested by scraping into PBS and isolated by centrifugation at $700 \mathrm{x} g$ for $5 \mathrm{~min}$, and cell pellets were stored at $-80^{\circ} \mathrm{C}$ until processing. 


\section{Western blot analysis}

Cells were lysed in ELB containing $50 \mathrm{mM}$ Hepes (pH 7), $250 \mathrm{mM} \mathrm{NaCl}, 5 \mathrm{mM}$ EDTA, 0.1\% Nonidet P-40, $10 \%$ glycerol, $0.5 \mathrm{mM}$ DTT, $0.5 \mathrm{mM}$ 4-(2-aminoethyl)benzenesulfonyl fluoride.HCl, $2 \mu \mathrm{g} / \mathrm{ml}$ leupeptin, $2 \mu \mathrm{g} / \mathrm{ml}$ aprotinin, $10 \mathrm{mM} \mathrm{NaF}$, and $50 \mathrm{mM} \beta$-glycerophosphate on ice for 15 $\min$, sonicated for $5-10 \mathrm{~s}$ and centrifuged at $20000 \mathrm{xg}$ for $15 \mathrm{~min}$ at $4^{\circ} \mathrm{C}$. Protein extracts $(20 \mu \mathrm{g}$, as determined by Bio-Rad Protein Assay (Bio-Rad)) were diluted in sample buffer (4 x Novex Nupage sample buffer), heated at $95^{\circ} \mathrm{C}$ for 5 min and separated by SDS-PAGE (4-12 \% and 3-8 \%)followed by blotting onto a nitrocellulose membrane using the NuPAGE-Novex BisTris (XCell SureLockTM) system (Invitrogen). Membranes were blocked with 5\% non-fat milk in Tris-buffered saline/0.1\% Tween (TBS-T) for one hour, incubated with primary antibody overnight at $4^{\circ} \mathrm{C}$, washed three times $10 \mathrm{~min}$ in TBS-T and incubated with horseradish peroxidise-labeled secondary antibodies for $1 \mathrm{~h}$ at room temperature. The membranes were then washed three times $10 \mathrm{~min}$ in TBS-T. Detection was achieved using ECL SuperSignal West Femto Maximum Sensitivity Substrate (Pierce) together with a ChemiDoc XRS/Quantity One documentation system (Bio-Rad).

\section{Protein and DNA synthesis}

Cells were seeded at 8.000 cells/well in 96-well Cytostar-T plates and cultured overnight at $37^{\circ} \mathrm{C}$, $5 \% \mathrm{CO}_{2}$ in a humidified incubator. Growth medium was changed on the plates to $100 \mu \mathrm{l} /$ well RPMI containing 10\% FBS, $100 \mathrm{U} / \mathrm{ml}$ penicillin, $100 \mu \mathrm{g} / \mathrm{ml}$ streptomycin and $25 \mu \mathrm{g} / \mathrm{ml}$ gentamicin and $\left[{ }^{3} \mathrm{H}\right]$ thymidine $(0.4 \mu \mathrm{Ci} /$ well $)$ or $\left[{ }^{14} \mathrm{C}\right]$ leucine $(0.5 \mu \mathrm{Ci} / \mathrm{mL})$ respectively. Compounds were diluted in growth medium containing 10\% FCS. Compound dilutions were thereafter transferred to the cell plates by transfer of $100 \mu 1 /$ well resulting in a total volume of $200 \mu 1 /$ well containing final compound 
concentrations in $0.025 \%$ DMSO. Cell plates were incubated at $37{ }^{\circ} \mathrm{C}, 5 \% \mathrm{CO}_{2}$ in a humidified incubator. Scintillation readings were made at 1 hours and 2 hours the same cell plate by MicroBeta reader to determine amount of $\left[{ }^{3} \mathrm{H}\right]$ thymidine or $\left[{ }^{14} \mathrm{C}\right]$ Leucine incorporated into DNA or Protein respectively.

\section{Caspase assay}

Cells were seeded at 8.000cells/well in 96-well black Packard Viewplates and cultured overnight at $37^{\circ} \mathrm{C}, 5 \% \mathrm{CO}_{2}$ in a humidified incubator. Growth medium was changed on the plates to $100 \mu \mathrm{l} /$ well RPMI containing $10 \% \mathrm{FBS}, 100 \mathrm{U} / \mathrm{ml}$ penicillin, $100 \mu \mathrm{g} / \mathrm{ml}$ streptomycin and $25 \mu \mathrm{g} / \mathrm{ml}$ gentamicin. Compounds were diluted in compound plates in growth medium containing $10 \%$ FCS. Compounds were thereafter transferred to the cell plates by transfer of $100 \mu \mathrm{l} /$ well resulting in a total volume of $200 \mu \mathrm{l} /$ well containing final compound concentrations in $0.025 \%$ DMSO. Cell plates were incubated with compounds at $37{ }^{\circ} \mathrm{C}, 5 \% \mathrm{CO}_{2}$ in a humidified incubator. Caspase assays were run at 4, 6 or 22 hour time-points, one plate per time-point. Caspase activity was measured using “ApoONE® Homogeneous Caspase-3/7 Assay" kit from Promega according to manufactures instructions. Flourescence was read in a fluorescence plate reader using a $521 \mathrm{~nm}$ emission filter and a $499 \mathrm{~nm}$ exitation filter.

\section{Viability and cell death assays}

For AlamarBlue, cells were plated in black Packard/Perkin Elmer 96-viewplates. Cell densities were estimated based on growth during the assay to $80-90 \%$ confluency. The day after plating, the growth medium was changed on the plates to $100 \mu \mathrm{l} /$ well RPMI containing $10 \% \mathrm{FBS}, 100 \mathrm{U} / \mathrm{ml}$ penicillin, $100 \mu \mathrm{g} / \mathrm{ml}$ streptomycin and $25 \mu \mathrm{g} / \mathrm{ml}$ gentamicin. Compounds were diluted in growth medium containing $10 \%$ FCS. Compounds were thereafter transferred to the cell plates by transfer 
of $100 \mu \mathrm{l} /$ well resulting in a total volume of $200 \mu \mathrm{l} /$ well containing final compound concentrations in $0.025 \%$ DMSO. Terfenedine $50 \mu \mathrm{M}$ was used as a control for maximal cell kill. Cell plates were incubated with compounds for 72 hours at $37^{\circ} \mathrm{C}, 5 \% \mathrm{CO}_{2}$, and $95 \%$ humidity. The number of viable cells was estimated using AlamarBlue. AlamarBlue signal was read in a fluorescence plate reader using a 590nm emission filter and a 530nm exitation filter.

Cell viability and dose-response curves were measured by WST-1 proliferation assay (Roche) according to manufactorers instructions and the setup described above. Apoptotic cells were determined in an Olympus IX microscope with the UV channel by counting condensed nuclei in cells stained with cell-permeable Hoeschst 33342 2,5 $\mu \mathrm{g} / \mathrm{ml}$ (Sigma-Aldrich) for $10 \mathrm{~min}$. Three randomly chosen fields containing a minimum of 100 cells were counted.

\section{Clonogenic assay}

In vitro colony forming assays were performed essentially to the same protocol as outlined in (19). Briefly, cells were cultured with compounds and seeded onto $35 \mathrm{~mm}$ dishes in $3 \%(\mathrm{w} / \mathrm{v})$ agar containing a sheep erythrocyte feeder layer. Agar plates were cultured for $14-21$ days at $37^{\circ} \mathrm{C}$ and colonies counted using a digital colony counter and Sorcerer image analysis software (Perceptive Instruments Ltd, SuVolk, UK). Data were analysed using GraphPad Prism (GraphPad Software, CA, USA) and Calcusyn (Biosoft, Cambridge, UK) as appropriate.

\section{Metabolism study}

Metabolon Inc., performed metabolic profiling and data analysis on thirty MCF-7 pellet samples consisting of six replicates of cells treated with $100 \mathrm{nM}$ TOP216 or DMSO control. Cell pellets were analyzed at three time points $(0,4.5$ and $24 \mathrm{~h})$, with $\mathrm{t}=0 \mathrm{~h}$ being the time of drug administration. The extracted supernatant was split into equal parts for analysis on the GC and LC 
platforms. All samples were randomly distributed across a single day platform run on GC/MS and LC/MS/MS instrumentation, and they were analyzed using Welch's two sample T-test.

\section{Xenograft studies}

The anti-tumour effect of TOP216 in vivo was tested in a MCF-7, MDA-MB-468, A2780, MiaPaca and in a PC-3 subcutaneous (s.c.) xenograft models. 10e7 carcinoma cells in $200 \mu$ RPMI medium were injected s.c. in Balb/c nude mice twenty four hours after whole body irradiation with a $\gamma$ source $\left(2.0 \mathrm{~Gy}, \mathrm{Co}^{60}\right)$. The drinking water was complemented with $1.25 \mathrm{mg} / \mathrm{ml}$ of $\beta$-oestradiol (Sigma) to support growth of hormone dependent MCF-7 cells. Mice were randomized and treatment started at a mean volume of $194 \pm 150 \mathrm{~mm}^{3}$ (117 days after the graft). The study was performed by Oncodesign, France.

The PC-3 (CRL-1435, ATCC) human prostate cancer cells were grown in RPMI $+10 \%$ FBS, washed once with PBS and 10e7 cells were suspended in $100 \mu$ l of PBS + 100 $\mu 1$ matrigel (BD) and injected s.c. in female NMRI/nude mice (Taconic). Treatment started at a mean volume of $403 \pm$ $192 \mathrm{~mm}^{3}$ (31 days after the graft). Oral treatment with TOP216 was given once weekly for four weeks. The study was performed by TopoTarget A/S, Denmark. TOP216 was formulated in $2 \%$ DMSO, 5\% Tween80 and 93\% isotonic saline and applied at $10 \mathrm{ml} / \mathrm{kg}$ (i.v. or p.o.). For i.v. treatment, the mice received 10 or $50 \mathrm{mg} / \mathrm{kg} / \mathrm{week}$, and for p.o. treatment the mice received 100 mg/kg/week. In the MCF-7, MDA-MB-648, MiaPaca and A2780 study Paclitaxel (TAXOL ${ }^{\circledR}, 6$ $\mathrm{mg} / \mathrm{ml}$, from Bristol-Myers Squibb), $15 \mathrm{mg} / \mathrm{kg} /$ week i.v. ( $5 \mathrm{ml} / \mathrm{kg}$ ) was included as a positive control for tumour growth inhibition. Tumour diameters were measured during tumour growth and tumour volumes (Tv) estimated according to the formula: $\mathrm{Tv}=\left(\right.$ width $^{2} \mathrm{x}$ length $) / 2$. 


\section{PharmacoKinetics}

A Water Quattro Premier LC-MS-MS system was used for bioanalysis. Plasma samples were precipitated with acetonitrile containing $1 \mu \mathrm{g} / \mathrm{ml}{ }^{13} \mathrm{C}$-labelled TOP216 ( 1:3) and separation from it major metabolite was performed by $0.05 \%$ formic acid -acetonitrile gradient on a Waters Sunfire C18 column $(2.1 \times 50 \mathrm{~mm} 3.5$ um particles $)$ operated at $40^{\circ} \mathrm{C}$. Detection was performed by Electrospray ionisation in the positive mode (Cone voltage $15.0 \mathrm{~V}$ and Collision Energy 15.0V). A transition $354.10 \mathrm{~m} / \mathrm{z}>260.10 \mathrm{~m} / \mathrm{z}$ and $366.2 \mathrm{~m} / \mathrm{z}>266.10 \mathrm{~m} / \mathrm{z}$ was used for TOP216 and the internal standard, respectively. The linear range was from $70 \mathrm{ng} / \mathrm{ml}$ to $500 \mu \mathrm{g} / \mathrm{ml}(\mathrm{r}=0.998)$, the RSD for 5 repeated determinations in the range from $100-10000 \mathrm{ng} / \mathrm{ml}$ was better that $12.1 \%$ and accuracy ranged from 81-93\%. Analysis of Serum and Hematologic parameters was performed by Oncodesign, France. 


\section{RESULTS}

\section{Close analogues of the oxyphenisatin derivatives TOP216, TOP001 and TOP385 show similar}

anti-proliferative activities in the $\mathrm{nM}$ range

The antiproliferative activity of the close analogues TOP001, TOP216 and TOP385 were tested on a broad spectrum of cancer cell lines using clonogenic assays, AlamarBlue and WST-1 proliferation assays (Table 1). TOP216, TOP001 and TOP385 showed inhibition of cell proliferation at low nanomolar concentrations in drug responsive cell lines as well as similar dose-response curves tested on MCF-7 and PC-3 cell lines ( Fig. 1A and data not shown). The parental compound TOP001 was tested for dose-response inhibition of cell proliferation on a spectrum of human breastderived non-cancerous and cancer cell lines: MDA-MB-231, MDA-MB-435S, MDA-MB-453, MDA-MB-468, SKBr-3, BT-474, BT-549, MCF-7, MCF-10A (non-cancerous), T-47D and ZR751. TOP001 induced a strong and dose-dependent inhibition of proliferation in this spectrum of cell lines, with MDA-MB-435s, MDA-MB-231 and the non-cancerous cell line MCF-10A being highly insensitive (<1000 fold as compared to sensitive lines) to the treatment TOP001 (Fig. 1B). The lead compound TOP216 was further analysed in clonogenic assays for dose-response inhibition of cell proliferation of selected cell lines, MCF7, A2780 and the insensitive cell line MDA-MB-231(Data not shown) as well as the effect of TOP216 on cellular protein and DNA synthesis was measured (Fig. 1C). TOP216 treatment at $100 \mathrm{nM}$ strongly inhibited protein synthesis and DNA synthesis rates in responsive MCF-7 cell line within 1-2 hours as measured by leucine and thymidine incorporation respectively. Effects of TOP001 and TOP216 on cell death markers and induction of cell death were also evaluated to establish whether the mechanism of inhibition of cell proliferation involves a cytostatic or cytotoxic mechanism (Fig. 1D-E). While a marked and rapid activation of caspase 3/7 was noted in cell lines such as BT-474, MCF-7, MDA-453, SK-BR-3 and T-47D, caspase activation was not apparent in non-responsive cell lines such as MDA-231 and MDA-435 
and in the MDA-MB-468 cell line although morphological alterations were noted. These data show that the TOP-analogues exhibit pro-apoptotic effects in most drug responsive human breast cancer cell lines, and that the MDA-MB-468 cell line may represent an exception to this rule. The cytotoxic activity of TOP216 was investigated using Hoechst-33342 staining of apoptotic cells (Fig. 1E). Indeed treatment with TOP216 at $200 \mathrm{nM}$ for 20 hours induced cell death of MCF-7 cells. Importantly pre-treatment with the pharmacological general caspase inhibitor, z-VAD-fmk $100 \mu \mathrm{M}$, exhibitited significant protection against TOP216 induced cell death(Fig. 1E). In conclusion the TOP analogues dose-dependently inhibit cell proliferation at low nanomolar concentrations and induce caspase dependent apoptosis of cancer cells.

\section{The optimized analogue TOP216 induces significant alterations in intracellular metabolite} levels

To obtain further insight into the mechanism of action of the lead compound, we used metabolic profiling with the aim to get an unbiased, global assessment of the action and effects of TOP216 by screening for changes in biochemical metabolites. This profiling was performed on sensitive MCF7 cells treated with drug (100 nM) for $0,4 \frac{1}{2}$ and 24 h respectively. Full data curation of the MCF-7 pellets yielded 170 named metabolites. Welch's two sample T-test was performed on the control group vs. drug treated group and revealed that at $4.5 \mathrm{~h}$ and $24 \mathrm{~h}, 71$ and 112 metabolites, respectively, were significantly changed ( $\mathrm{p}$-value $<0.05$ ), indicating that TOP216 treatment results in profound changes in intracellular metabolism and the choice of cellular energy source (Fig. 2 and Supplementary table 2).

Most notably TOP216 caused a dramatic reduction in intracellular amino acid levels, several as high as 10 -fold. Decreases in amino acids were more dramatic at $4.5 \mathrm{~h}$ compared to $24 \mathrm{~h}$, as opposed to changes in sugars and lipids, which were more pronounced at $24 \mathrm{~h}$. 
Glucose, and TCA-cycle metabolites, such as citrate, alpha-ketoglutarate, succinate, malate, were all significantly increased in the TOP216 group (up to 3-fold), indicating that the drug altered the central energy metabolism of the cell.

Also, the nucleotide metabolites adenine, guanine, ATP, CMP and TMP were significantly increased in the TOP216 group at $24 \mathrm{~h}$, whereas other nucleotide metabolites were significantly decreased, including hypoxanthine, inosine, adenosine, guanosine, uridine, AMP and UMP. These differences may be reflective of alterations in DNA/RNA synthesis or breakdown induced by TOP216.

5-methylthioadenosine (5-MTA) was significantly increased in the drug group, while the polyamines spermidine and putrescine were decreased. 5-MTA and polyamines are involved in the regulation of cell proliferation and apoptosis, which is in agreement with the drug affecting these pathways. Taken together, TOP216 dramatically affects the breast cancer cell metabolism, possibly as a result of the great reduction of intracellular amino acids rapidly induced by the drug.

\section{TOP216 regulates mTOR and AMPK activity.}

The mTOR signalling pathway controls the rate of protein synthesis in response to intracellular amino acid levels by phosphorylation of its substrates p70S6K and 4EBP-1(11, 14). Based both on the dramatic effect of TOP216 on intracellular amino acid levels and energy metabolism, we hypothesized that this compound inhibits mTOR signaling. In agreement with this TOP216 treatment $(100 \mathrm{nM})$ of MCF7 cells caused a time-dependent decrease in the phosphorylation of p70S6K (FIG. 3A). As general energy metabolism was affected by treatment with TOP216, we also investigated the activation status of AMP kinase, a key metabolic regulator and energy sensor, by phosphorylation status of its downstream effector, Acetyl-CoA carboxylase (ACC). TOP216 treatment $(100 \mathrm{nM})$ of MCF-7 cells over a $24 \mathrm{~h}$ time course caused a time-dependent increase in the 
phosphorylation levels of ACC (FIG. 3A). Akt phosphorylation levels were not affected by the compound (data not shown) suggesting that AMPK activation and mTOR inhibition may be involved in the mechanism of inhibition of cancer cell growth by this compound, probably induced by the block of amino acid uptake.

\section{TOP216 treatment activates the GNC2 amino acid sensing pathway.}

Under conditions of amino acid deprivation, the translation initiation factor eIF $2 \alpha$ is phosphorylated by GCN2. This strongly inhibits general protein synthesis while only allowing translation of few selected mRNAs $(4,16,17)$. Since mTOR inhibition generally leads to a mild decrease in overall protein synthesis, and TOP216 strongly inhibited protein synthesis, the effect of TOP216 on regulating the activity of eIF2 $\alpha$ was assessed by western blotting. Indeed, TOP216 treatment (100 $\mathrm{nM}$ ) of MCF-7 cells over a $24 \mathrm{~h}$ time course showed a time-dependent increase of the phosphorylation levels of $\left(\operatorname{Ser}^{51}\right)$ eIF2 $\alpha$ (Fig.3B). Next we investigated if the increased phorphorylation level of eIF2 $\alpha$ was due to GCN2 activation as a result of uncharged tRNAs. In support with this notion TOP216 treatment of MCF-7 cells lead to an induction of phosphorylated GCN2 (Fig. 3B). In addition the levels of phosprorylated GCN2 in the insensitive cell line MDAMB-231 was not increased in response to treatment with compound indicating that activation of GCN2 is specific to the anti proliferative mechanism of action of the compound (Fig. 3C). These results further support the observation that treatment with TOP216 affects the intracellular amino acid levels possibly by decreased amino acid uptake. 


\section{TOP216 shows strong antitumorigenic effect in vivo}

The TOP216 compound was well tolerated in mice. In vivo safety studies of max tolerated doses in nude mice suggest no major adverse effects following oral, intraperitoneal (P.O.; I.P.), or intravenous (I.V.) administration using the highest feasible dose of the current formulations: 85 $\mathrm{mg} / \mathrm{kg}$ (IV) and $17 \mathrm{mg} / \mathrm{kg}$ (oral). Lethality, body weight reduction or gross clinical signs were not observed following either single dose administration at 50\%, 66\% and $100 \%$ of the highest feasible dose, or multiple administration schedules (P.O. or I.P.; once daily for 14 da'ys; I.V.; once weekly for 4 weeks). These data suggest that the max tolerated doses for P.O. administration of TOP216 is $>170 \mathrm{mg} / \mathrm{kg}$, and $>85 \mathrm{mg} / \mathrm{kg}$ for I.V. administration. Clinical chemical analysis on serum samples revealed no abnormalities following dosing of animals with TOP216. Similarly, hematological analysis revealed no drug effects on blood cell types, haemoglobin content or hemocrit using P.O. dosing. I.V. dosing also had no effect, although a reduction in platelet number was apparent in I.V. treatment groups, which appeared to be due to higher than expected platelet count in the vehicle control (Data not shown). LC-MS-MS was used for bio analysis of drug plasma content of TOP216 in nude mice. TOP216 were administered P.O. at increasing dose levels from 10 to $100 \mathrm{mg} / \mathrm{kg}$. Plasma drug content was then analysed in sequential blood samples collected $1 \mathrm{~min}-24$ hours following drug administration (Fig.4A).

In nude mice carrying MCF-7 breast, PC-3 prostate (Fig. 4), MDA-MB-468 breast, A2780 ovary, or MiaPaca pancreas (Supplementary Fig. 1) tumors, TOP216 was well tolerated and displayed significant anti-tumor activity. Both oral (P.O.; $20 \mathrm{mg} / \mathrm{kg}$ and $100 \mathrm{mg} / \mathrm{kg}$; Q1Dx15; once daily for 15 days) and I.V. (10mg/kg and $50 \mathrm{mg} / \mathrm{kg}$; Q1Dx4; once weekly for 4 weeks) administration of TOP216 dramatically reduced MCF-7 tumour growth compared to vehicle control groups (Fig. 4BC). The T/C value was $6-17 \%$ at the end of the P.O. treatment period; marked tumour regression as 
apparent in all animals $(\mathrm{n}=8)$ with mean tumour volumes $\sim 20 \%$ of the original size (For MDA-MB468, A2780 and MiaPaca xenograft models see Supplementary Fig. 1). Tumour shrinkage continued after cessation of dosing (T/C values of 2 - 4\%; tumour volumes $<10 \%$ of original size). Using I.V. dosing, T/C values were $3 \%$ and $6 \%$ at the end of the administration period using 10 $\mathrm{mg} / \mathrm{kg}$ and $50 \mathrm{mg} / \mathrm{kg}$ TOP216 respectively (once weekly for 4 weeks). Marked tumour regression was noted at both doses in all animals; tumours were $<10 \%$ of the original size. Paclitaxel treatment groups were included in the study for comparator purposes. Treatment with $15 \mathrm{mg} / \mathrm{kg}$ paclitaxel (IV; Q7Dx4; weekly for 4 weeks) reduced tumour growth rate ( $\mathrm{T} / \mathrm{C}=63 \%$ at termination of dosing) and resulted in less pronounced tumour regression. A combination group (100 mg/kg PO TOP216 $+5 \mathrm{mg} / \mathrm{kg}$ paclitaxel) was also included, but the extreme effects of TOP216 alone precluded meaningful analysis.

In the PC-3 model TOP216 was given as an oral treatment $(100 \mathrm{mg} / \mathrm{kg} /$ week $)$ that was initiated at tumor sizes up to $750 \mathrm{~mm}^{3}$. Tumor regression was observed after the first treatment, and regression continued during the treatment period with no tumor re-growth within the observation period of the experiment (until at least 35 days after the initial dose) (Fig. 4D). I.V (5-50 mg/kg) treatment in the PC3 xenograft model also resulted in tumor growth delay and regression (Fig. 4E).

MCF-7 xenografts treated with TOP216 for 4, 24, 48 and 72 hours were furthermore subjected to analysis of eIF2 $\alpha$ prhosphorylation levels and the activation status of the mTOR pathway and by western blotting (Fig. 4F). Indeed a rapid induction of the phosphorylation of eIF2 $\alpha$ was observed in tumors taken out after 4 and 24 hours treatment with TOP216 (50mg/kg I.V.). In addition the analysed MCF-7 tumors showed loss of mTOR pathway activation at 24, 48 and 72 hours (Fig. 4F). Taken together these data clearly show the potency and antitumorgenic potential of TOP216. 


\section{DISCUSSION}

TOP001 and the chemically optimized analogues TOP216 and TOP385 are structurally related members of a compound series with remarkable anti-cancer properties(18). However the mechanism of action by which this novel compound class mediates these strong anti-cancer and anti-proliferative effects is not clear.

The present study documents TOP001 and lead compound TOP216 as novel apoptosis inducing anti-cancer compounds that show inhibition of cell proliferation at low nano molar concentrations. Several studies have pointed to an important role of translational control in cancer development (20). In addition to inhibiting cellular proliferation we found that a functional consequence of TOP216 treatment of MCF-7 cells was a rapid and dramatic decrease in global protein and DNA synthesis.

The metabolome of a cancer cell is likely to show changes after responding to an anti-cancer drug $(3,21)$. These changes can be used to explain observed effects of treatment of cell lines with the anti-cancer drug and eventually indicate its mechanism of action. A global assessment of the action and effects of TOP216 was therefore provided by screening for changes in biochemical metabolites. Strikingly, TOP216 induced a dramatic drop in intracellular amino acid levels, in several cases up to 10 fold as measured after $4.5 \mathrm{~h}$ of TOP216 treatment of sensitive MCF-7 cells.

Deficiency of amino acids is sensed by the kinase GCN2 by a mechanism that involves uncharged tRNA binding to a regulatory HisRS domain, homologous to histidyl tRNA synthetase enzymes, within the kinase. This leads to auto-activation of its kinase domain and allows phosphorylation of the translational initiation factor eIF2 $\alpha$, which in turn inhibits recycling of eIF2 $\alpha$ to its active GTPbound form, and thereby reduces general protein synthesis(4). As expected from the observed metabolomic effects of the compound, treatment of the MCF-7 cell line with $100 \mathrm{nM}$ TOP216 increased phosphorylation of eIF2 $\alpha$ and GCN2 supporting the above notion. 
The mTOR signalling pathway also senses and responds to the levels amino acids, by controlling the rates of protein synthesis accordingly. Important substrates of mTOR are $\mathrm{p} 70^{\mathrm{S} 6 \mathrm{~K}}$, and $4 \mathrm{E}-\mathrm{BP} 1$. Both are consequently dephosphorylated during mTOR inhibition in response to low intracellular amino acid levels, thereby leading to inhibition of protein synthesis(14, 22). TOP216 treatment of MCF-7 cells strongly decreased the phosphorylation levels of $\mathrm{p} 70^{\mathrm{S} 6 \mathrm{~K}}$.

Interestingly dysregulation of mTOR function via physiologic or mutational activation of upstream pathways is a common event in tumors from many linages. However, the clinical antitumor activity of mTORC1 inhibitor analogues such as rapamycin has been modest at best, since these drugs seem to primarily promote tumor growth stasis. O'Reilly et al. showed that mTORC1 inhibition leads to activation of PI3K/Akt and proposed this as a possible reason for the limited efficacy of rapamycin in epithelial cancers (23-25). In contrast to mTORC1 inhibitors, the TOP analogues do not lead to activation of Akt and inhibit translation both via mTOR and eIF2 $\alpha$ supporting the strong in vivo efficacy of these drugs. TOP216 induced tumour stasis and regression (including cures) in mouse xenograft models of human breast, prostate, ovarian and pancreatic cancer, both when administrated intravenously and per-orally (Fig. 4 and Supplemental Fig. 2). Large PC-3, MCF-7, MDA-MB-468, Miapaca and A2780 tumors were shown to regress following per-oral and intravenous dosing of TOP216 respectively, and regression continued during the treatment period with no re-growth for as long as the animals were observed.

In addition to affecting mTOR activity, these data highlight a further important facet of cell biology, namely that amino acid provision can be used physiologically or pharmacologically to control cell proliferation. Interestingly Paul Nicklin et al. recently showed that cellular uptake of Lglutamine by SLC15A is the rate limiting step for essential amino acid- and growth factor regulation of mTORC1, as the bidirectional transporter SLC7A5/SCL3A2 uses intracellular Lglutamine as an efflux substrate to regulate the uptake of L-leucine which subsequently leads to 
activation of mTORC1. Previous studies have shown that, in general, human tumor cells are significantly more sensitive to amino acid deprivation than normal cells. There is widespread upregulation in human tumors of certain amino acid transporters, presumably to meet the increased demands for essential amino acids to take part in protein synthesis and cellular metabolism [3, 23]. It may be this increased demand for amino acids in tumor cells that underlies the effects of TOP216 and analogues.. In conclusion the strong inhibitory effect of the TOP216 on cancer cell proliferation and as well as the potent antitumorigenic effect on human tumor xenografts, suggests that these novel anti-cancer drugs, presumably targeting amino acid uptake, may represent new and useful tool in the treatment of human cancers. Extensive comparative studies in sensitive and insensitive cell lines with the aim of establishing the details of the mechanism of action of the TOP analogues and to address the role of this compound group in amino acid transport are currently being carried out. 


\section{REFERENCES}

1. Kilberg MS, Pan YX, Chen H, Leung-Pineda V. Nutritional control of gene expression: how mammalian cells respond to amino acid limitation. Annu Rev Nutr 2005; 25:59-85. 2. Kimball SR, Jefferson LS. New functions for amino acids: effects on gene transcription and translation. Am J Clin Nutr 2006; 83:500S-7S.

3. Kroemer G, Pouyssegur J. Tumor cell metabolism: cancer's Achilles' heel. Cancer Cell 2008; 13:472-82.

4. Zhang P, McGrath BC, Reinert J, et al. The GCN2 eIF2alpha kinase is required for adaptation to amino acid deprivation in mice. Mol Cell Biol 2002; 22:6681-8.

5. Avruch J, Long X, Ortiz-Vega S, Rapley J, Papageorgiou A, Dai N. Amino acid regulation of TOR complex 1. Am J Physiol Endocrinol Metab 2009; 296:E592-602.

6. Fingar DC, Blenis J. Target of rapamycin (TOR): an integrator of nutrient and growth factor signals and coordinator of cell growth and cell cycle progression. Oncogene 2004; 23:315171.

7. Goberdhan DC, Boyd CA. mTOR: dissecting regulation and mechanism of action to understand human disease. Biochem Soc Trans 2009; 37:213-6.

8. Goberdhan DC, Ogmundsdottir MH, Kazi S, et al. Amino acid sensing and mTOR regulation: inside or out? Biochem Soc Trans 2009; 37:248-52.

9. Huang J, Dibble CC, Matsuzaki M, Manning BD. The TSC1-TSC2 complex is required for proper activation of mTOR complex 2. Mol Cell Biol 2008; 28:4104-15.

10. Huang J, Manning BD. The TSC1-TSC2 complex: a molecular switchboard controlling cell growth. Biochem J 2008; 412:179-90. 
11. Hara K, Yonezawa K, Weng QP, Kozlowski MT, Belham C, Avruch J. Amino acid sufficiency and mTOR regulate p70 S6 kinase and eIF-4E BP1 through a common effector mechanism. J Biol Chem 1998; 273:14484-94.

12. Sancak Y, Peterson TR, Shaul YD, et al. The Rag GTPases bind raptor and mediate amino acid signaling to mTORC1. Science 2008; 320:1496-501.

13. Sancak Y, Sabatini DM. Rag proteins regulate amino-acid-induced mTORC1 signalling. Biochem Soc Trans 2009; 37:289-90.

14. Wang X, Campbell LE, Miller CM, Proud CG. Amino acid availability regulates p70 S6 kinase and multiple translation factors. Biochem J 1998; 334 ( Pt 1):261-7.

15. Sood R, Porter AC, Olsen DA, Cavener DR, Wek RC. A mammalian homologue of GCN2 protein kinase important for translational control by phosphorylation of eukaryotic initiation factor-2alpha. Genetics 2000; 154:787-801.

16. Wek RC. eIF-2 kinases: regulators of general and gene-specific translation initiation. Trends Biochem Sci 1994; 19:491-6.

17. Wek SA, Zhu S, Wek RC. The histidyl-tRNA synthetase-related sequence in the eIF-2 alpha protein kinase GCN2 interacts with tRNA and is required for activation in response to starvation for different amino acids. Mol Cell Biol 1995; 15:4497-506.

18. Uddin MK, Reignier SG, Coulter T, et al. Syntheses and antiproliferative evaluation of oxyphenisatin derivatives. Bioorg Med Chem Lett 2007; 17:2854-7.

19. Roed H, Christensen IB, Vindelov LL, Spang-Thomsen M, Hansen HH. Interexperiment variation and dependence on culture conditions in assaying the chemosensitivity of human small cell lung cancer cell lines. Eur J Cancer Clin Oncol 1987; 23:177-86.

20. Hanahan D, Weinberg RA. The hallmarks of cancer. Cell 2000; 100:57-70. 
21. Vander Heiden MG, Cantley LC, Thompson CB. Understanding the Warburg effect: the metabolic requirements of cell proliferation. Science $2009 ; 324: 1029-33$.

22. Nicklin P, Bergman P, Zhang B, et al. Bidirectional transport of amino acids regulates mTOR and autophagy. Cell 2009; 136:521-34.

23. Easton JB, Kurmasheva RT, Houghton PJ. IRS-1: auditing the effectiveness of mTOR inhibitors. Cancer Cell 2006; 9:153-5.

24. O'Reilly KE, Rojo F, She QB, et al. mTOR inhibition induces upstream receptor tyrosine kinase signaling and activates Akt. Cancer Res 2006; 66:1500-8.

25. Wan X, Harkavy B, Shen N, Grohar P, Helman LJ. Rapamycin induces feedback activation of Akt signaling through an IGF-1R-dependent mechanism. Oncogene 2007; 26:1932-40. 


\section{TABLES AND FIGURES}

TABLE 1. Chemical structures and inhibition of tumor cell growth by TOP001, TOP216 and TOP385. The IC-50 values are in nanomolar scale.
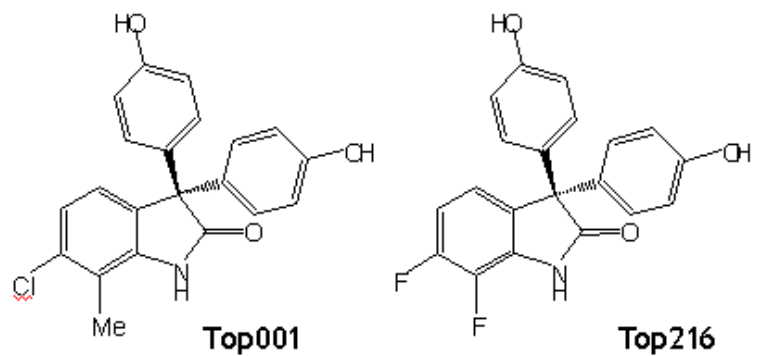

\begin{tabular}{|c|c|c|c|c|c|c|c|}
\hline species & Tissue & status & cell line & IC-50 (nM): & TOP001 & TOP216 & TOP385 \\
\hline human & prostate & carcinoma & DU145 & & 20 & 8 & 30 \\
\hline human & prostate & carcinoma & LNCaP & & 30 & 8 & \\
\hline human & prostate & carcinoma & PC3 & & 22 & 8 & 22 \\
\hline human & Glioma & carcinoma & U-251 & & 5000 & 5000 & 5000 \\
\hline human & Glioma & carcinoma & LN18 & & 5000 & 5000 & 5000 \\
\hline human & Glioma & carcinoma & U87MG & & 30 & 9 & 200 \\
\hline human & melanoma & carcinoma & LOX-IMVI & & 80 & 10 & 50 \\
\hline human & melanoma & carcinoma & Malme 3M & & inactive & inactive & inactive \\
\hline human & Colon & carcinoma & HT29 & & 1000 & 500 & 500 \\
\hline human & Colon & carcinoma & НСТ-15 & & 90 & 15 & 40 \\
\hline human & Colon & carcinoma & SW620 & & inactive & inactive & inactive \\
\hline human & Ovary & carcinoma & OVCAR-3 & & 7 & 3 & 10 \\
\hline human & Ovary & carcinoma & A2780 & & 30 & 7 & \\
\hline human & Ovary & carcinoma & SK-OV-3 & & $>1000$ & $>1000$ & $>1000$ \\
\hline human & Lung & carcinoma & $\mathrm{NCl}-\mathrm{H} 23$ & & 20 & 20 & 20 \\
\hline human & Lung & carcinoma & A549 & & inactive & inactive & inactive \\
\hline human & Lung & carcinoma & NCl-H226 & & 1000 & 50 & 300 \\
\hline human & mamma & carcinoma & MDA-MB-231 & & inactive & inactive & inactive \\
\hline human & mamma & carcinoma & MDA-MB-361 & & 3 & 1 & 6 \\
\hline human & mamma & carcinoma & T47D & & 7 & 3 & 11 \\
\hline human & mamma & carcinoma & BT549 & & 11 & 2 & 11 \\
\hline human & mamma & carcinoma & MCF-7 & & 10 & 4 & 20 \\
\hline
\end{tabular}

Cells were cultured with compounds and seeded onto $35 \mathrm{~mm}$ dishes in $3 \%(\mathrm{w} / \mathrm{v})$ agar containing a sheep erythrocyte feeder layer. Agar plates were cultured for $14-21$ days at $37^{\circ} \mathrm{C}$ and colonies 
counted using a digital colony counter and Sorcerer image analysis software (Perceptive Instruments Ltd, SuVolk, UK). Data were analysed using GraphPad Prism The average $\mathrm{IC}_{50}$ values in $\mathrm{nM}$ scale represent mean values of at least three independent expreiments carried out in triplicates.

Figure 1. TOP001 and TOP216 induce time- and dose-dependent inhibition of cell proliferation and cell death in a spectrum of human cancer cell lines (A) MCF-7 breast cancer cells were seeded at 3000cells1/well(96-well) 24 hours before treatment with indicated concentrations of TOP001, TOP216 and TOP383 for 72 hours. The viability of the cells was determined by WST-1 proliferation assay. (B) Dose-response curves for a panel of breast cancer cell lines. Cells were seeded at 3000cells/well(96-well) 24 hours before treatment with indicated concentrations of TOP001 for 72 hours. The viability of the cells was determined by WST-1 proliferation assay. (C) Inhibition of protein and DNA synthesis by TOP216. MCF7 cells was seeded at 8.000cells/well(96well) 24 hours before addition of $[3 \mathrm{H}]$-thymidine or [14C]-Leucine and 100nM TOP216. Scintillation readings were started after one hour. Inhibition of protein- and DNA synthesis is expressed percentage of synthesis of non-treated cells. (D) Effects of TOP001 on caspase activation in human breast cancer cells. Caspase activity was measured using "Apo-ONE® Homogeneous Caspase-3/7 Assay" kit. (E) TOP216 induces caspase dependent cell death of MCF-7 cancer cells. MCF-7 cells were left untreated or treated with $200 \mathrm{nM}$ of TOP216 for 24 hours before staining the DNA with membrane permeable Hoechst-33342. When indicated, the pan-caspase inhibitor zVAD-fmk $(100 \mu \mathrm{mol} / \mathrm{L})$ was added 1 hour before TOP216. The viability of the cells was determined by counting apoptotic cells with condensed chromatin and is expressed as a percentage 
of untreated cells. TNF $10 \mathrm{ng} / \mathrm{ml}$ was used as positive control for cell death. Colums and graphs represent, means of at least two independent experiments carried out in triplicate $(n=6)$.

Figure 2 TOP216 induces a significant decrease in intracellular amino acid levels and alters the levels of many metabolites. Fold changes after TOP216 treatment of MCF7 cells at $100 \mathrm{nM}$ for 4.5 and 24 hours are shown for selected significantly changed metabolites.

Figure 3 TOP216 affects mTOR and GCN2 signalling. (A) Western blot analysis of phosphorylation status of p70S6K and ACC in protein samples from MCF7 cells. MCF-7 cells were left untreated or treated for 1, 4 and 24 hours respectively with 100nM TOP216. (B-C) Effect of TOP216 (100 nM) GCN2 and eIF2 $\alpha$ phosphorylation in MCF-7 and MDA-MB-231 cells over $24 \mathrm{~h}$ course. Levels p70S6K, ACC, GCN2 and eIF2 $\alpha$ were used as internal control for individual experiments.

Figure 4 TOP216 induces pronounced tumour regression. A-D 10e7 carcinoma cells in $200 \mu l$ RPMI medium were injected s.c. in Balb/c nude mice twenty four hours after whole body irradiation with a $\gamma$-source (2.0 Gy, Co60) (A) Pharmacokinetic profile of TOP216 in nude mice. (B) Effect of TOP216 at indicated doses (I.V. weekly for 4 weeks) on tumour volume in a MCF-7 breast cancer xenograft model in Balb/c mice, $(n=8)$. (C) Effect of TOP216 at indicated doses and taxol $(5 \mathrm{mg} / \mathrm{kg})$ in combination with TOP216 P.O. daily for 15 days on tumour volume in a MCF-7 breast cancer xenograft model in Balb/c mice, (n=8) (D) Effect of TOP216, $100 \mathrm{mg} / \mathrm{kg} \times 1$ P.O./week $\mathrm{x} 4$ weeks on large tumors in PC-3 prostate cancer xenograft model in Balb/c mice, $(n=8)$. (E) Effect of TOP216 at indicated doses, x 1 I.V./week x 4 weeks on tumor growth in PC-3 prostate cancer xenograft model in Balb/c mice, $(n=8)$. (F) Western blot analysis of phosphorylation 
status of p70S6K and eIF2 $\alpha$ after treatment with TOP216 (I.V. 50mg/kg) for 4, 24, 48 and 72 hours of MCF-7 xenografts. 